\title{
Retinal Graft-Mediated Pupillary Responses in Rats: Restoration of a Reflex Function in the Mature Mammalian Brain
}

\author{
Henry Klassen and Raymond D. Lund \\ Department of Neurobiology, Anatomy and Cell Science, School of Medicine, Pittsburgh, Pennsylvania 15261
}

\begin{abstract}
We have shown previously that fetal retinae transplanted to neonatal rat brains are capable of making the pretectal connections necessary for driving a pupillary reflex in response to light. At birth, the rat brain is still developing and presents a favorable environment for fiber outgrowth and synaptogenesis. A remaining question is whether such grafts will also establish functional connections within the less plastic mature brain. Fetal retinae taken from Sprague-Dawley rats at embryonic day 13 or 14 were implanted in the pretectal region of mature host rats ranging in age from 6 to 11 weeks. The contralateral host eye was removed to reduce afferent competition within the pretectum between the optic input of graft and host. The remaining host optic nerve was cut before testing to eliminate all remaining host visual input. Beginning 1 month after transplantation, the retinae were surgically exposed and illuminated.
\end{abstract}

In 6 of 24 animals, illumination elicited an obvious pupilloconstriction response in the host eye. The magnitude of this graft-mediated response varied between animals. Two animals produced very brisk responses, comparable to the best results seen following transplantation into neonatal hosts. In these cases, the degree of constriction was clearly dependent on the level of graft illumination. The 4 other animals produced responses that were less brisk. All 6 animals with clear-cut graft-mediated pupillary responses had well-formed grafts containing numerous rosettes and ganglion cells. In addition to these 6 animals, 9 others showed extremely small or variable pupillary changes on graft illumination. The remaining 9 animals showed no stimulus-associated pupillary activity. Grafts in this group tended to be poorly formed or were located outside the pretectal area. These results show that transplanted retinae are capable of making specific functional connections with the mature brain, since an appropriate visual reflex can be elicited by illuminating the graft in the absence of host visual input.

There is now a large literature showing that transplanted neural tissue can become incorporated into the mammalian CNS and modify the functional responses of the host. These grafts affect

\footnotetext{
Received June 21, 1989; revised Aug. 4, 1989; accepted Aug. 9, 1989.

This work was supported by NIH Grant EY05283 (R.D.L.) and by grants from the Edmond and Marianne Blaauw Ophthalmology Fund through Sigma Xi (H.K.) and the Emmerling Fund of the Pittsburgh Foundation. H.K. is a Mellon Fellow. We wish to thank Dr. Ian Pollack and Michael Young for their comments on the manuscript, and Fran Shagas for technical assistance.

Correspondence should be addressed to Raymond D. Lund, Department of Neurobiology, Anatomy and Cell Science, School of Medicine, 3550 Terrace St., Pittsburgh, PA 15261.

Copyright (C) 1990 Society for Neuroscience $0270-6474 / 90 / 100578-10 \$ 02.00 / 0$
}

the neural activity of the recipient brain by a number of fundamentally different mechanisms. The mechanism operating in a particular case depends on both the type of implanted tissue and the site of implantation (see Björklund et al., 1987, for review). For instance, dopamine-producing cells grafted into the striatum (Björklund and Stenevi, 1979) and basal forebrain cells grafted into the hippocampus or cerebral cortex (Gage et al., 1984) can modulate host relay systems. Neural grafts may also produce functional effects by exerting a trophic influence on host neural tissue (Bregman and Reier, 1986; Rosenberg et al., 1988) or by neuroendocrine secretion (Krieger et al., 1982; Gibson et al., 1984). Yet another role for grafts is to provide a substrate allowing damaged central neurites to regain access to target nuclei (Aguayo et al., 1981; Gage et al., 1985; Vidal-Sanz et al., 1987). Finally, in addition to aiding in the modulation or regrowth of relay systems, neural grafts can also function as integrated elements within such a system by actually encoding information and relaying it to the host brain. Behavioral recovcry mediated by neural implants into a relay system has been demonstrated using striatal grafts placed in lesioned striatum (Deckel et al., 1983, 1986; Isacson et al., 1984, 1986) and retinal grafts placed over the midbrain (Klassen and Lund, 1987, 1988a). Retinal grafts are responsive to illumination and relay this information to host visual centers (Simons and Lund, 1985; Craner et al., 1989). The host brain can, in turn, respond to graft input with visually driven behaviors, such as the pupillary light reflex (Klassen and Lund, 1987, 1988a).

The majority of previous retinal transplantation studies used neonatal rodents as recipients. Introduction of neural tissue at this age has several advantages: the graft can be introduced with minimal trauma to host brain structures, and axons from an intracranial implant are capable of growing considerable distances in the immature brain to reach their target (McLoon and Lund, 1980). This is in contrast to previous studies using adult recipients where retinae transplanted to the tcctal region did not differentiate or form projections as well as similar grafts placed in neonatal rats (McLoon and Lund, 1983; Lund et al., 1987). Limited penetrance of axons in the brain of mature recipients has also been noted in other transplant situations (Björklund et al., 1976, 1980; Vidal-Sanz et al., 1987; see also Azmitia and Björklund, 1987). Although retinal grafts make only sparse projections to the adult brain, a previous investigation of the functional capabilities of fetal eyes transplanted to the brains of adult rats has shown that these grafts produce ERG-like potentials in response to flashes of light (Freed and Wyatt, 1980). We, therefore, questioned whether retinal grafts implanted near the retinorecipient areas of adult brains could also establish functional graft-host connections as seen after transplantation to neonates. 
In this study, embryonic retinae were transplanted into the brains of adult rats, close to the olivary pretectal nucleus. Neurons located in this nucleus participate in the pupillary light reflex (Trejo and Cicerone, 1984; Campbell and Lieberman, 1985; Clarke and Ikeda, 1985). This was done to test whether retinal grafts can establish a pathway within the mature brain sufficient to mediate a simple visual behavior. A preliminary rcport of this work has appeared elsewhere (Klassen and Lund, 1988b).

\section{Materials and Methods}

Preparation of donor tissue. Donor retinae were taken from fetal Sprague-Dawley rats at 13 or $14 \mathrm{~d}$ gestation. Timed-pregnant females were anesthetized with diethyl ether and, using sterile technique, an abdominal incision was made through which the uterine horns were externalized. The wall of the uterus and the embryonic membranes were cut, and the embryos were extruded into a petri dish of ice-cold F-10 culture medium (Gibco). The eyes of the embryos were removed, their lenses extracted, and the retina dissected free from the surrounding tissue. Isolated retinae were transferred to a petri dish of ice-cold medium, awaiting transplantation to the host. This wait did not cxceed $2 \mathrm{hr}$ for any given retina, a time period that has yielded good results in previous work using neonatal hosts.

Host animals. Twenty-four mature Sprague-Dawley rats ranging in age from 6 to 11 weeks at the time of transplantation were used as hosts. Animals were anesthetized with tribromoethanol during all surgical procedures, including testing. Because previous work has indicated that the projections made by retinal grafts to the adult brain are not as extensive as those made to the neonatal brain (McLoon and Lund, 1983; Lund et al., 1987), it was expected that the grafts would have to be very close to the appropriate target region if the desired graft-host connections were to be established. To facilitate accurate placement of the retinae, the dorsal surface of the brain stem was exposed by removing the overlying cortex so that the pretectum on one side could be directly visualized. In some cases, transplantation immediatcly followed cxposure of the pretectum, whereas in others, the wound was closed and later reopened for transplantation after 2 weeks or more. At that time, all blood resulting from the previous surgery had disappeared from the surface of the brain stem, thereby facilitating placement of the graft.

The eye contralateral to the graft was removed to eliminate most of the host optic input to the pretectum on the side of the brain receiving the fetal retina. This was done with the expectation of promoting innervation of the host as noted following transplantation into neonates (McLoon and Lund, 1980). Eye removal was done at birth, at the time of brain stem exposure, or immediately after transplantation.

At the time of transplantation, 1-3 of the isolated fetal retinae were drawn into a glass micropipette attached to a $50 \mu l$ Hamilton syringe; the pipette was inserted into the parenchyma of the pretectal region under direct vision, and the retinal tissuc was injectcd. The scalp incision was closed, and the animal was allowed to recover.

For comparison purposes, animals were available from parallel studies in which retinae were transplanted to neonatal rats. The subsequent treatment was identical to that of the present study.

Assessment of pupillary activity and tissue processing. The animals were tested at 10 weeks to 9 months of age. The interval between introduction of the transplant and testing for pupillary activity was always at least $30 \mathrm{~d}$ to allow time for fiber outgrowth and the establishment of graft-host connections. The longest interval between transplantation and testing was 6 months (mean $=98 \mathrm{~d}$ ).

Before testing for graft-mediated pupillary activity, the remaining optic nerve was cut intracranially to eliminate all host optic input to the brain but preserve the efferent pupilloconstriction pathway traveling with the oculomotor nerve. Immediately after the optic nerve was cut, or up to $5 \mathrm{~d}$ later, the graft was surgically exposed and illuminated with a fiberoptic light source. Pupillary activity was recorded on videotape by a Panasonic Digital 5000 camera mounted on the surgical microscope. A character generator with built-in stopwatch displayed the time (in 0.1-sec increments) on the recording. Tapes were played back frame by frame, and the pupillary diameter was measured at regular intervals and corrected for magnification. Immediately after testing, the animals were perfused transcardially with $4 \%$ paraformaldehyde in PBS. Brains were removed and placed in $30 \%$ sucrose in PBS (at $4^{\circ} \mathrm{C}$ ) for cryoprotection. Sections were cut at a thickness of 30 or $40 \mu \mathrm{m}$ on a freezing
Table 1. Summary of pupillary reflex parameters from the animals with clear responses

\begin{tabular}{lllll} 
Animal & $\begin{array}{l}\text { Percent } \\
\text { constriction }\end{array}$ & $\begin{array}{l}\text { Latency } \\
(\mathrm{sec})\end{array}$ & $\begin{array}{l}\text { Duration } \\
(\mathrm{sec})\end{array}$ & $\begin{array}{l}\text { Initial } \\
\text { baseline } \\
\text { diameter } \\
(\mathrm{mm})\end{array}$ \\
\hline 1 & 33 & 0.8 & 1.8 & 1.4 \\
2 & 33 & 0.8 & 3.2 & 3.2 \\
3 & 18 & 3.3 & 16.6 & 3.3 \\
4 & 12 & 3.2 & 5.5 & 3.5 \\
5 & 8 & 2.7 & 4.9 & 4.2 \\
6 & 15 & 9.2 & 20.8 & 4.0
\end{tabular}

The responses of animals 1,2 , and 3 are graphed in Figures $1, A, C$, and $3 A$, respectively.

microtome. Adjacent sections were stained with cresyl violet and with a Nauta-Gygax silver stain modified to stain neuronal fibers (Lund and Westrum, 1966).

Controls. Six mature Sprague-Dawley rats from a single litter underwent the same surgical procedures and testing as experimental animals except that they did not receive fetal retinae. At either 5 or 9 weeks of age, the cortex over the pretectum was removed on one side and the contralateral eye was enucleated. Testing was done at 11 weeks of age, following optic nerve transection.

\section{Results}

\section{Pupillary responses}

Illumination resulted in a clear and consistent pupillary reflex in 6 of 24 animals. The parameters of these responses are listed in Table 1. In 2 of these animals (Fig. 1), the graft-mediated reflexes were comparable in briskness to the best responses obtained from animals that received retinae as neonates (Fig. 2A). As in the previous studies (Klassen and Lund, 1987, 1988a), it was possible to demonstrate that the degree of host eye pupilloconstriction was dependent on the intensity of the light stimulating the graft. The effect of luminance level on pupillary diameter was assessed by varying the intensity of illumination or by interposing filters of varying density between the light source and the animal. Within the range of the behavioral response, the diameter of the host pupil varied inversely with illumination intensity (Fig. 2B).

In 9 of the 24 animals, there was low-amplitude pupillary activity that either was very slow or not evoked consistently by photic stimulation. Although such activity could not be definitively identified as a light reflex, it did appear to be initiated by photic stimulation in that the pupillary activity predictably followed the onset of illumination. A typical example is shown in Figure $3 C$, where a small but reliable change in pupillary diameter was seen shortly after the onset of graft illumination. Similar responses have been observed in animals that received grafts at birth but were poorly innervated by them (Lund et al., 1989).

Pupillary activity was not seen in the 8 remaining animals with grafts (Fig. $4 A$ ) or in 1 experimental and 6 control animals without grafts. The controls ensure that the pupillary responses seen in the other animals were not due to incidental stimulation of other inputs or brain structures, such as the pineal body. The probability of randomly obtaining pupillary responses in 15 of the 24 experimental animals, but in none of the 6 control animals, is 0.017 using the Fisher exact test with a 2-tailed region of rejection (Siegel, 1956). 

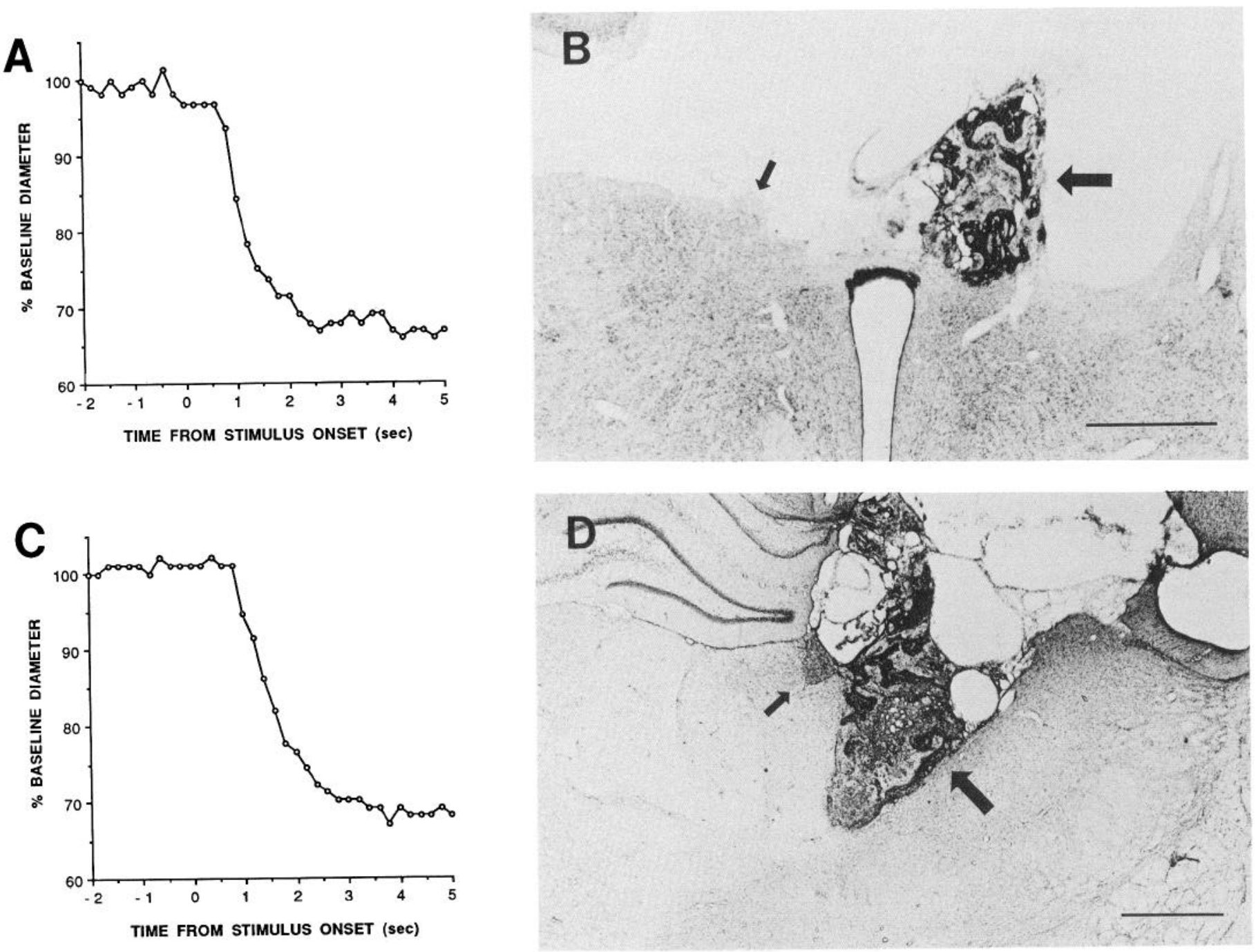

Figure 1. Behavioral and anatomical correlates of the best performing grafts. $A$ and $B$ are from animal 1 (Table 1$)$. $C$ and $D$ are from animal 2 . In $A$ and $C$, continuous illumination of the grafts, beginning at time $=0$, was followed by rapid constriction of the host pupils. In $B$ and $D$, Nisslstained coronal sections show the positions of the retinal grafts (large arrows). In $B$, the graft is fused with the pretectum. The position of the pupilloconstriction center can be discerned on the contralateral side of the brain (small arrow). The morphology of the ipsilateral pretectum has been distorted by the implantation procedure. In $D$, the graft is embedded in the dorsal thalamus. The caudal limit of this graft was approximately $100 \mu \mathrm{m}$ from the rostral end of the olivary pretectal nucleus. The location of the habenula is indicated by the small arrow. Scale bars, $1 \mathrm{~mm}$.

\section{Timing of experimental manipulations}

Although every animal in this experiment received the same surgical manipulations, they differed in regard to the timing of these procedures. The age of the host at the time of transplantation, the period of time between transplantation and testing, the age of the host at the time of optic deafferentation, and the time between brain stem exposure and transplantation were varied between litters to investigate whether any particular set of conditions had an effect on responsiveness. Although the number of variables precluded identification of a particular set of conditions that might result in minor improvements in the response, it was clear that no single procedure had a dramatic effect on responsiveness. Both optimal responders and nonresponders were found in each group.

\section{Histological features of the grafts}

The transplanted retinae survived, differentiated, and grew to $2 \mathrm{~mm}$ or more in diameter. Although the pretectum was the intended site of implantation, some of the grafts were found in other brain stem locations or were adherent to the overlying cortex. In a number of cases, multiple retinae could be distinguished within the host brain, although they appeared to fuse at points of mutual contact. The grafts frequently developed a laminar organization consisting of recognizable retinal layers. In places, the normal, sheet-like organization of the laminae was replaced by rosettes in which the retinal layers were inverted (Fig. 5A). Photoreceptors within well-formed rosettes had an orderly array of inner segments, as well as a filamentous border that has previously been shown, at the ultrastructural level, to contain outer segments (Fig. 5B) (Matthews et al., 1982; Lund and McLoon, 1983). Associated with this filamentous border, in the center of rosettes, were large cells that have been identified immunohistochemically as microglia (Perry and Lund, 1989).

As a group, these grafts were less organized than retinae placed in neonates, in accord with previous studies of retinae placed in adult hosts (McLoon and Lund, 1983; Lund et al., 1987). Some grafts, however, attained a highly laminar organization 
that exhibited all the cellular and plexiform layers characteristic of normal retinae. These grafts appeared to have differentiated just as fully as retinae transplanted to the brains of neonates, except that the ganglion cell layer appeared to be more sparsely populated (Fig. 6). Although an optic fiber layer could be seen in grafts overlying the pretectum, the course of these fibers in the host brain could not be followed in normal silver preparations because of the complexity of host fiber patterns in the region.

In many grafts, the rosettes were poorly formed and less abundant than in retinae implanted at birth. Poorly structured grafts were dominated by areas consisting of haphazard collections of cell types. Neither inner nor outer segments could be discerned at the light microscopic level on photoreceptors situated in these less structured arrangements. In a number of grafts, the lamination was limited to segregation into cell-rich and cell-sparse zones (Fig. 4B). These poorly formed grafts had few, if any, identifiable ganglion cells or optic fiber bundles. A relatively frequent finding was foci of nonretinal tissue within the grafts, often resembling fragments of lens. Four grafts in this study were heavily infiltrated by small cells, with effacement of retinal architecture and tissue necrosis (Fig. $4 D$ ) indicative of immunological rejection by the host (Lund et al., 1987). This differs from our previous experience with allografts placed in newborns, which are very rarely rejected. More commonly, grafts in this study exhibited a mild degree of perivascular cuffing that was confined to a minority of the vessels within the graft, without effacement of graft cytoarchitecture.

\section{Functional correlates of structure}

The grafts that demonstrated clear pupillary responses were notable in that they were among the better differentiated grafts, with well-defined retinal layers (Fig. 5). They were also more closely apposed to the host pretectum (Figs. 1, $B, D ; 3, B, D$ ). These grafts contained abundant well-formed rosettes, inside of which a well-organized layer corresponding to the photoreceptor inner segments could be clearly discerned (Fig. $5 B$ ), appearing as a pink band when stained with cresyl violet. Pale filamentous material could be seen along the inner surface of these bands, presumably corresponding to photoreceptor outer segments.

Most unresponsive grafts were poorly organized or in an advanced state of rejection. In 2 cases, however, nonfunctional grafts largely resembled other grafts that had been functional. These grafts were similarly positioned, exhibited excellent laminar cytoarchitecture, and contained at least some well-formed rosettes. In these cases, the reason for the lack of functional behavior was less evident. It was noted, however, that despite being well laminated, both of these grafts appeared to lack the large, readily identifiable ganglion cells that were conspicuous in functional grafts.

\section{Discussion}

The results of this study demonstrate that retinae implanted in the mature mammalian brain, as in the neonate brain, can develop the proper cell types and precise functional connections necessary for the reconstitution of the pupillary light reflex. To accomplish this, the retinal grafts must be capable of encoding certain minimal stimulus parameters and relaying this information to the correct host neurons in an appropriate manner. These grafts, therefore, demonstrate a high degree of functional integration with host neural circuits and satisfy many of the criteria previously defined for substitution of function in a relay
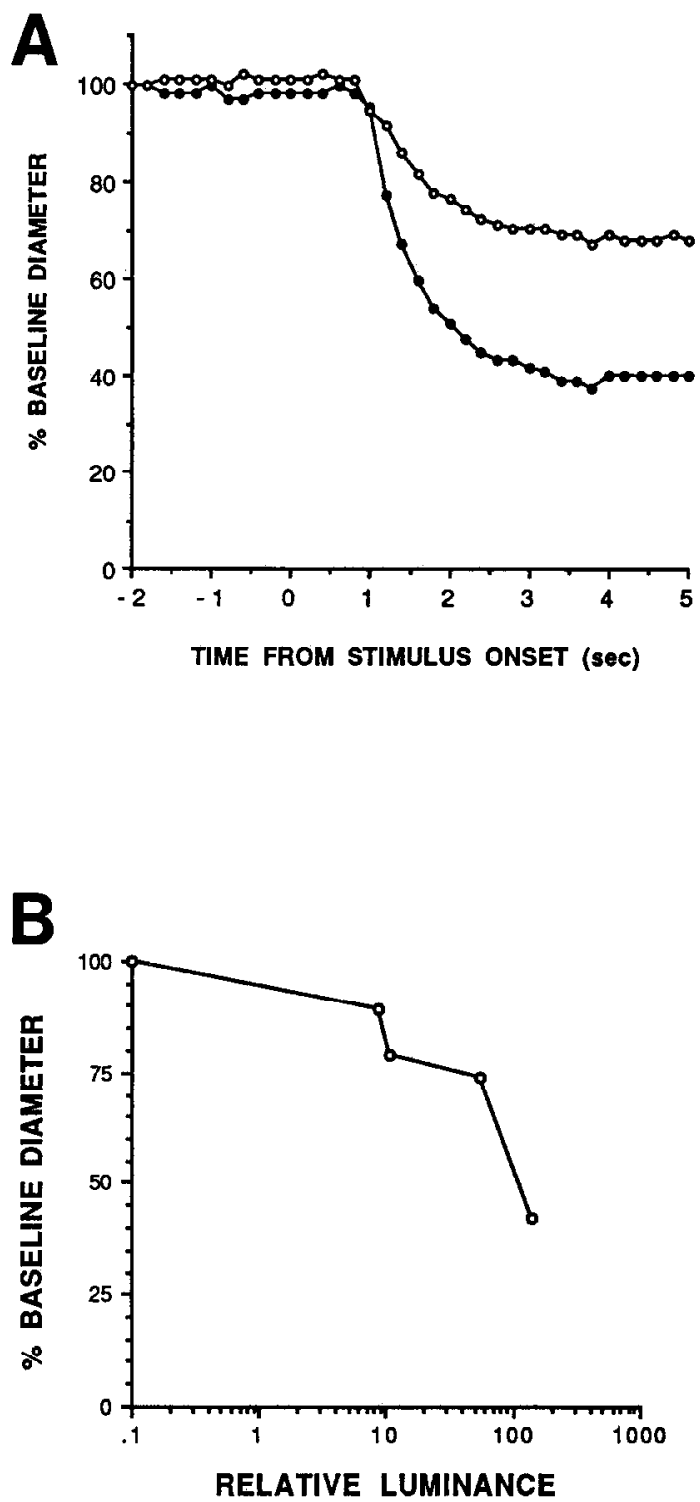

Figure 2. Pupillary activity following photic stimulation of retinal grafts. $A$, Comparison of the pupillary reflexes seen in rats that received retinal implants at different ages. A continuous stimulus was presented beginning at time $=0$. The animal whose response is represented by open circles is from the present study and was $51 \mathrm{~d}$ of age at the time of transplantation. Included for comparison is the response of an animal that received a retinal implant at birth (closed circles). Although exhibiting a lesser degree of constriction, the mature recipient produces a response that is quite brisk and similar to one of the best responses obtained from an animal grafted at birth. $B$, Resting pupillary diameter at different stimulus intensities in the mature recipient shown in $A$. Within the dynamic range of the graft, increments in luminance intensity resulted in smaller pupillary diameters.

system (Björklund et al., 1988; Buzsaki and Gage, 1988; see also Bartus, 1987).

\section{Behavioral findings}

The best graft-mediated pupillary reflexes seen in this study, using adult hosts, were as brisk as those previously seen after transplantation into neonates (Klassen and Lund, 1987), and, therefore, were almost as rapid as a normal reflex. However, a much smaller proportion of these adult hosts exhibited good responses than did animals receiving transplants at birth. 

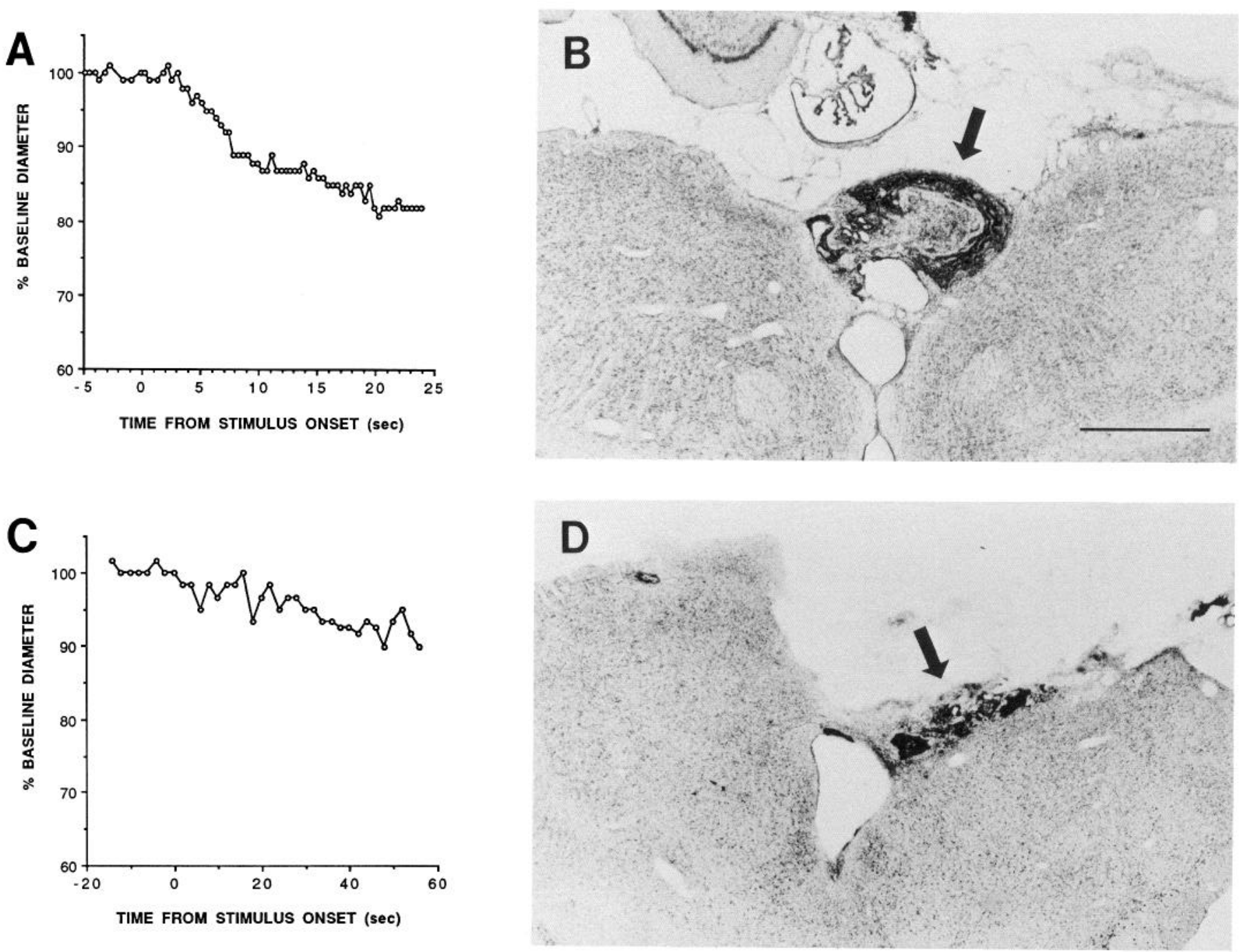

Figure 3. Behavioral and anatomical correlates of other functional grafts. $A$ and $B$ are from animal 3 (Table 1). $C$ and $D$ are from a graft functioning at a marginal level. $A$, Substantial pupillary constriction followed graft illumination although this response was not as large or rapid as those seen in Figure 1. Note that the response included small amplitude oscillations as well as periods of inactivity. $B$, The graft (arrow) was well laminated and embedded in the pretectum. A number of grafts did not produce clear pupillary reflexes but nevertheless demonstrated some stimulusassociated pupillary activity, such as that seen in $C$. Like the example shown $(D)$, these grafts were generally embedded in the pretectum $($ arrow) and contained areas of well-organized cytoarchitecture. Nissl stain. Scale bar, $1 \mathrm{~mm}$.

This lower incidence of functional recovery seemed to parallel the limited capacity of these grafts to innervate retinal targets in the mature brain, as well as the decreased frequency with which the grafts developed a well-laminated internal structure. The finding of a graft-mediated pupillary reflex in several animals indicates, however, that although the mature brain provides a less favorable environment for the differentiation of retinal grafts and the extension of ganglion cell axons, these factors do not constitute an insurmountable barrier to the repair of this particular relay function.

The present study cannot establish with certainty why many animals showed small or ambiguous changes in pupillary diameter. However, such activity correlated closely with graft illumination and was not seen in control animals without grafts. These changes did not resemble the slow, large-amplitude pupillary oscillations sometimes seen in animals under tribromoethanol anesthesia. Since animals with ambiguous responses generally had poorly differentiated grafts, the minimal pupillary activity possibly represents rudimentary light reactions by marginally functional grafts.

\section{Histology}

We found that retinal grafts placed in the brains of adult rats, like those placed in neonates, could attain a high degree of differentiation, including the characteristic retinal laminae and cell types. The laminae were often arranged into rosette formations, which are also seen in cultured retina (Tansley, 1933; La Vail and Hild, 1971) and in certain types of retinal pathology (Tso et al., 1969; Lahav et al., 1973).

Although fetal retinae transplanted into neonates also occasionally differentiate poorly, this outcome is common among retinae placed in adults, suggesting that maturation of the brain involves changes that decrease its ability to support the proper differentiation of grafted fetal retina. The nature of these agerelated changes remain unclear. Factors that may be involved include delayed or incomplete neovascularization of the grafts 

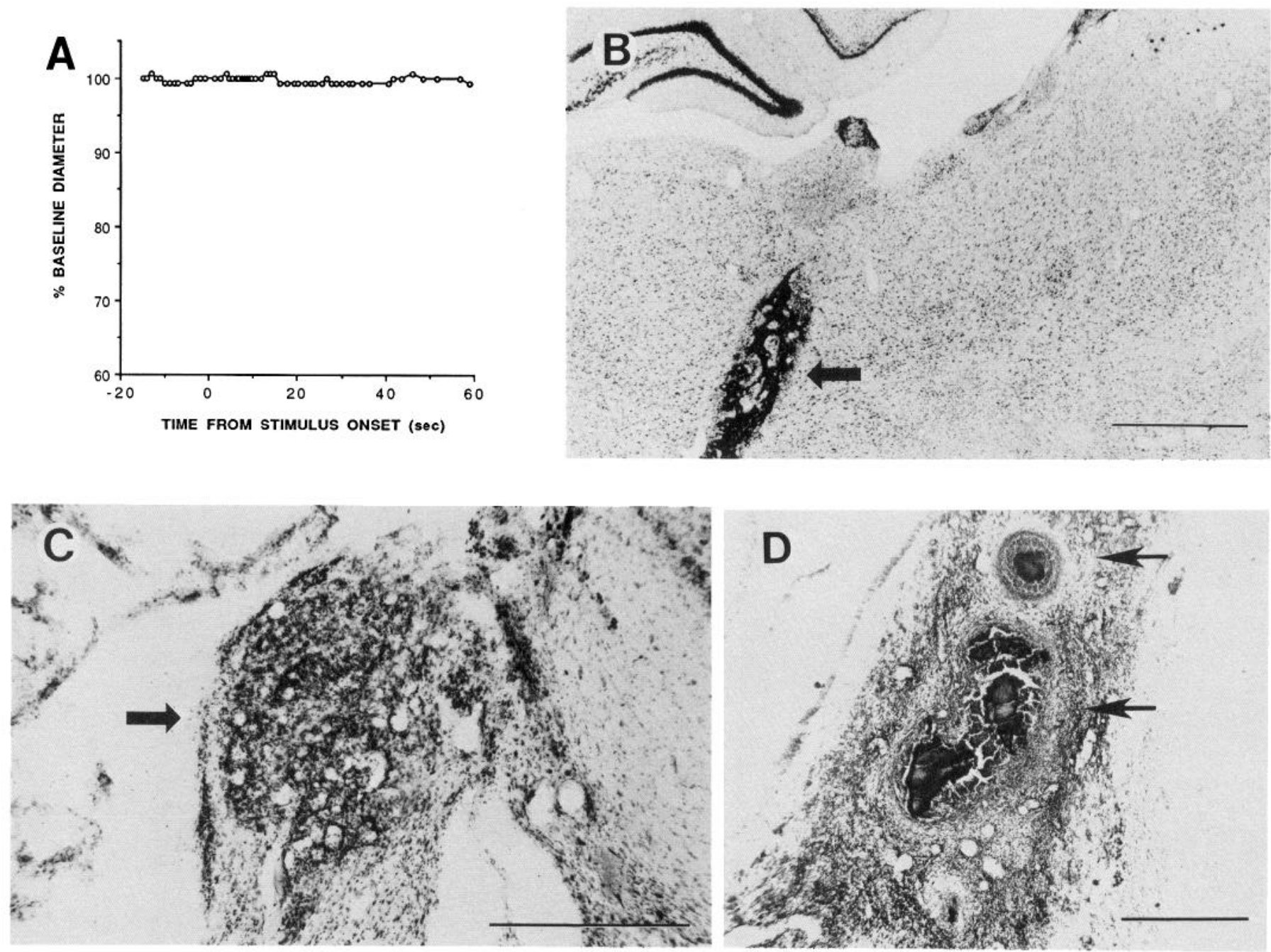

Figure 4. Examples of nonfunctional grafts. $A$, Graph showing absence of pupillary response to light. $B$, The graft that was illuminated in $A$. Note that the graft contains a degree of laminar structure but is embedded in the thalamus, rostral and deep to the pretectum. Scale bar, $1 \mathrm{~mm}$. $C$, Another example of a nonfunctional graft (arrow), which completely lacks laminar or rosetted cytoarchitecture. No grafts with such uniformly poor organization produced functional responses even if embedded in the pretectum. Scale bar, $500 \mu \mathrm{m}$. $D$, This graft is massively infiltrated by small cells, with areas of necrosis (arrows) indicative of an advanced stage of immunological attack. All sections were processed with a Nissl stain. Scale bar, $500 \mu \mathrm{m}$.

(Broadwell et al., 1988), differences in the status of the bloodbrain barrier within the graft vasculature (Svendgaard et al., 1975; Rosenstein, 1987), and age-related decreases in the expression of trophic factors (Nieto-Sampedro et al., 1983; Needels et al., 1986). Furthermore, it is not known whether the increased immunocompetence of the adult host might impede graft development, even in the absence of overt rejection.

Although some of the grafts in this study did demonstrate significant fiber outgrowth, this never rivaled that seen after transplantation at birth. In those cases in which the outgrowth could be resolved, the axons seemed to prefer traveling along the graft-host interface until reaching the target area rather than growing out across the host brain parenchyma. In a case where fibers did cross the parenchyma, they formed a reticulum around host blood vessels, one of the few laminin-containing sites in the brain of adult rats (Liesi, 1985). Laminin is a potent promoter of neurite outgrowth, which is transiently expressed along the path of optic axons during normal development in the rat (McLoon et al., 1988). In addition, the present study indicates that significant outgrowth across nonretinorecipient regions of mature brain is possible, since there was a $100 \mu \mathrm{m}$ gap between the olivary pretectal nucleus and a briskly functional graft.

Although fetal retinal allografts implanted at birth into Sprague-Dawley pups are rarely rejected, several of the grafts in this study showed clear signs of immunological rejection. This finding is consistent with previous work showing that the immune system of rats is immature at birth and that adult hosts require less immunogenetic disparity with the donor tissue (Lund et al., 1987). Another factor implicated in graft rejection is trauma to brain tissue during graft implantation (Lund et al., 1988), which was significantly greater in the adult hosts because of the necessity of removing intervening cortex to expose the dorsal midbrain, as well as the disruption associated with partially implanting the grafts in the pretectum.

\section{Comparison of graft histology with functional capacity}

The histological condition of the grafts was generally correlated with behavioral efficacy. Functional grafts showed good lami- 

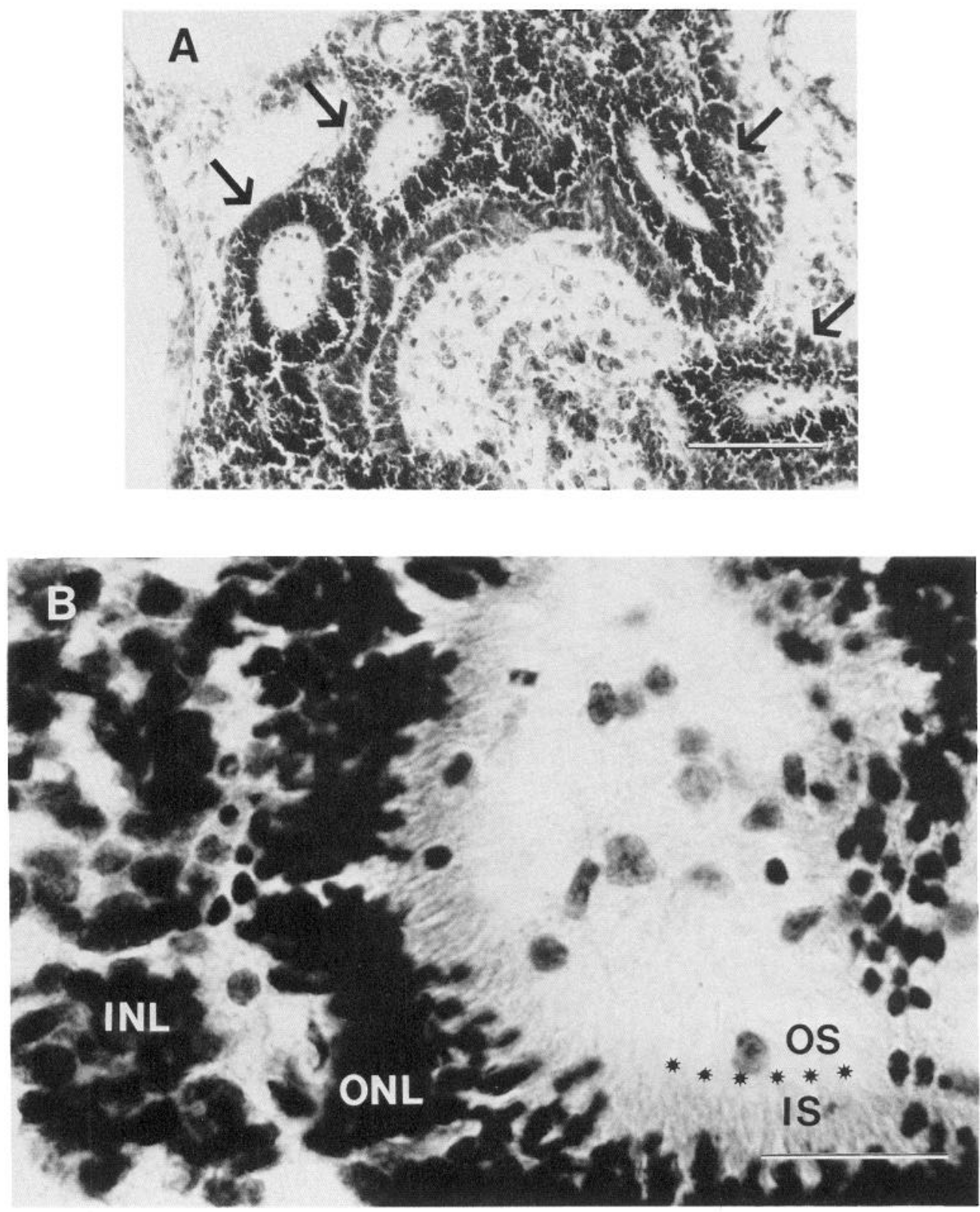

Figure 5. Histological details of a graft that produced a brisk pupillary response to light. $A$, This graft contains distinct laminae and numerous well-formed rosettes (arrows). Nissl stain. Scale bar, $100 \mu \mathrm{m}$. B, Detail of a rosette at high power showing the outer nuclear layer $(O N L)$, the layer corresponding to the photoreceptor inner segments $(I S)$, and the less organized material in the location of the outer segments $(O S)$. INL, inner nuclear layer. The approximate border between the inner and outer segments is indicated by asterisks. Nissl stain. Scale bar, $25 \mu \mathrm{m}$. $C$, A section

nation, evidence of outer segments, and abundant rosettes and contained identifiable ganglion cells and optic fiber bundles (Figs. $1,3,5)$. In accordance with previous studies, ganglion cells were not identified within grafts distant from the retinorecipient regions (Matthews et al., 1982; McCaffery et al., 1982; Sefton et al., 1987). Not surprisingly, such displaced grafts were ineffective in driving pupillary responses (Fig. 4).

Overall, although the histological findings correlated with the behavioral results, there were 2 apparent exceptions to the general trend. These grafts exhibited clear lamination yet were unresponsive to stimulation. It may be significant that the majority of the photoreceptors within these grafts were not arranged in rosettes but rather in the more conventional laminar sheets surrounding the outside of the graft. Although this structure is closer to that of normal retina, it is conceivable that such an arrangement might be less suited to graft function. Whereas the photoreceptor outer segments of the intact eye rely on an intimate relationship with the pigment epithelium for a number of important processes, including the transport of retinol from the blood, the regeneration of photopigment, and the phagocytosis of membranous disks (Dowling, 1960; Young and Bok, 1969; Bok and Heller, 1976), the transplanted neural retina, stripped of pigment epithelium, must use alternative strategies to carry out these functions. The formation of rosettes within the grafts creates an enclosed space that might provide a stable microenvironment conducive to the establishment of such functions. In fact, at the ultrastructural level, microglia can be seen within the centers of rosettes phagocytizing the membranous disks of photoreceptors (Perry and Lund, 1989). In contrast, photoreceptor laminae on the cisternal or ventricular surfaces of grafts 

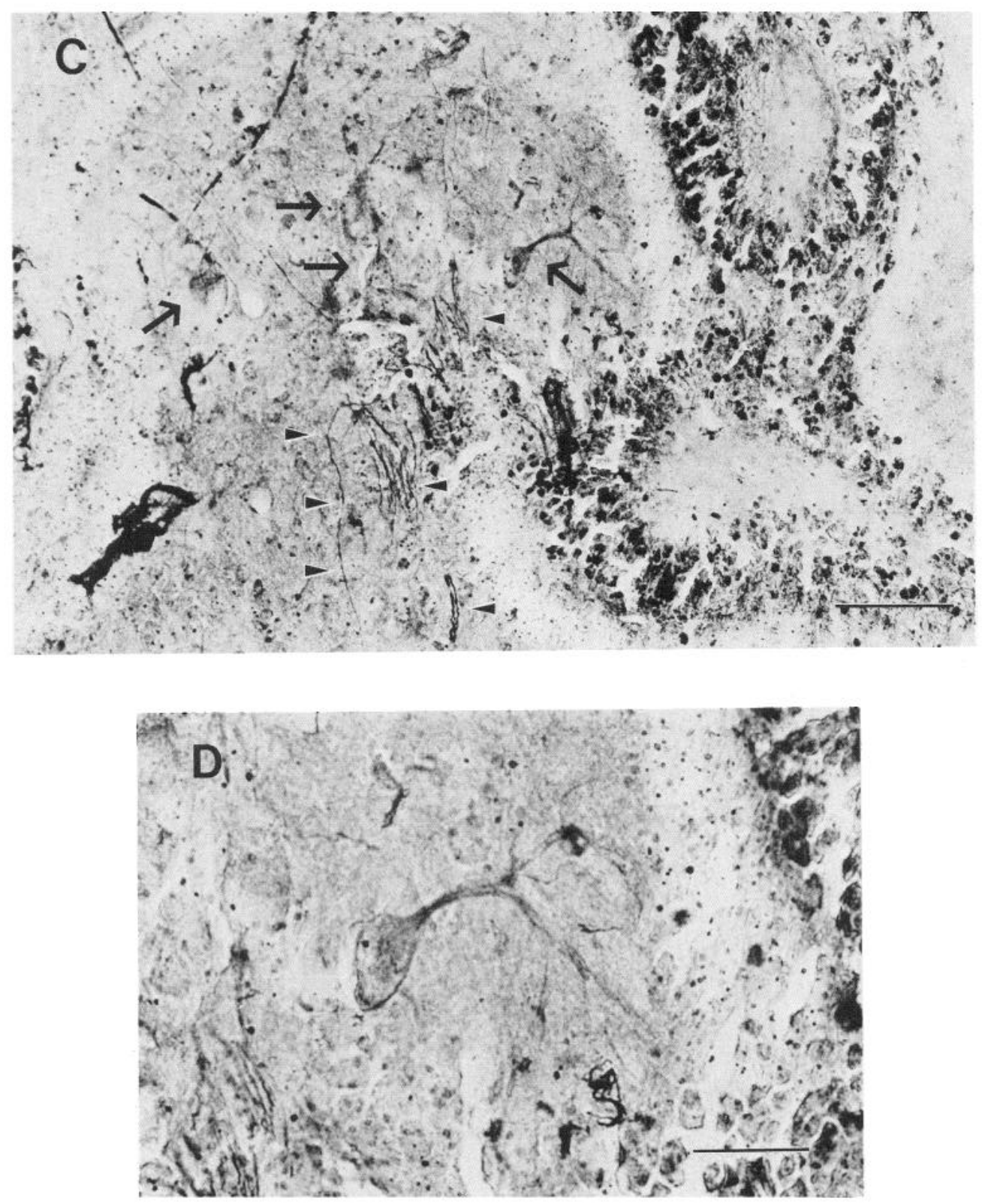

adjacent the one shown in $A$ processed with a silver stain and shown at higher power, demonstrating a layer of retinal ganglion cells (arrows) as well as a group of fibers that appear to be leaving this layer (arrowheads). Scale bar, $50 \mu \mathrm{m}$. $D$, High power view of a ganglion cell. Modified Nauta stain. Scale bar, $20 \mu \mathrm{m}$.

are oriented such that the outer segments are not sequestered but, instead, are exposed to the cerebrospinal fluid circulation.

\section{Reactive changes following deafferentation of host nuclei}

Also bearing on the functional efficacy of the grafts is the fact that eye removal in adults produces ultrastructural changes that are quite different from those seen after eye removal in neonates in that inhibitory interneurons play a greater role in synaptic reorganization following deafferentation in older animals (Lund and Lund, 1971; Campbell and Lieberman, 1985). Although the increase in local inhibitory synapses would seem to pose a potential difficulty for the restoration of effective excitatory input from the grafts, the functional significance of these changes is not known. It is interesting to note that, in this study, examples of good functional recovery were seen after optic deafferentation at birth or in adulthood.

\section{Experimental strategies}

Current transplantation studies directed toward the reintegration of isolated retina into the visual system can be divided into 3 different experimental strategies. In one group of studies, fetal or neonatal retinae have been transplanted to the vitreal chamber of the eye (Del Cerro et al., 1985, 1987; Turner and Blair, 1986; Blair and Turner, 1987). These grafts become vascularized and develop many features of normal retinae, but it has not yet been demonstrated whether they are responsive to light, and there is no evidence that axons from these grafts enter the optic nerve to reach the brain. A second strategy has focused on promoting the centripetal regeneration of damaged optic axons 

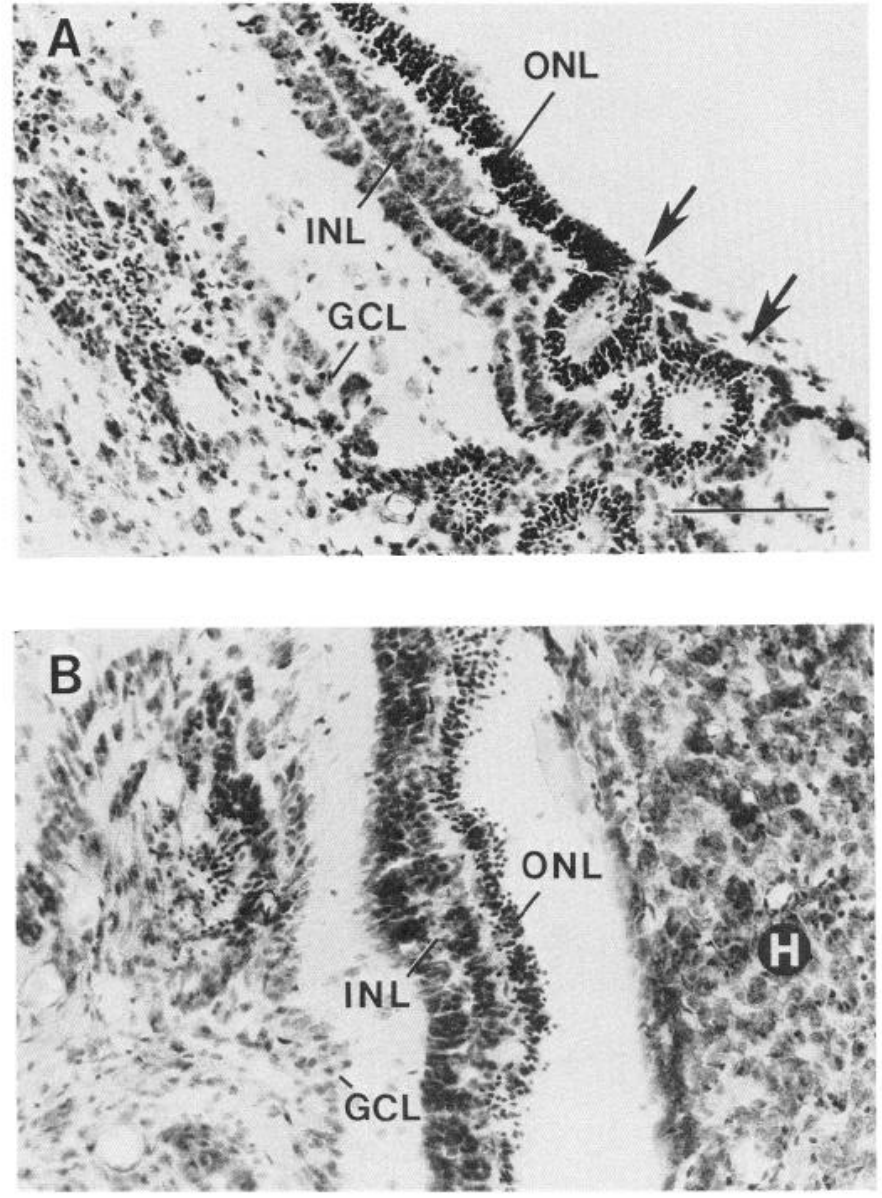

Figure 6. Retinal graft morphology. $A$, Well-differentiated intracranial graft in an animal that received a fetal retina at birth. The characteristic retinal layers are present: $O N L$, outer nuclear layer; $I N L$, inner nuclear layer (split); $G C L$, ganglion cell layer. Note the presence of rosettes (arrows). B, Graft in an animal that received a fetal retina at $46 \mathrm{~d}$ of age. This retina has also attained a high degree of laminar organization. The laminae are designated as before ( $H$, host brain). Nissl stain. Scale bar, $100 \mu \mathrm{m}$.

using sciatic nerve implants in adult rats (So and Aguayo, 1985; Vidal-Sanz et al., 1987). Up to $10 \%$ of the damaged axons enter the nerve tube, and a small percentage of these enter the superior colliculus, where they form synapses. Our studies represent a third approach in which a retinal graft is placed adjacent to the retinal target region, thereby circumventing the requirement for long-range axonal outgrowth and promoting the establishment of functional connections with the host brain.

Using these techniques in combination, it may be possible to reconstruct a functional circuit extending from an orthotopic retinal graft in the eye to retinal targets in the brain stem along a surrogate axonal substrate. Such a circuit could recreate the feedback properties of a normal light reflex where retinal illumination initiates a signal that results, by way of pupillary constriction, in decreased light reaching the photoreceptors.

In terms of higher visual functions, it remains to be shown whether projection fibers from peripheral nerve grafts distribute in a topographic manner (Vidal-Sanz et al., 1987). In fact, a study involving transplantation of retinae to the tectal region of newborn rats has indicated that even when these grafts project to the entire tectum, the projection still shows no evidence of topography (Galli et al., 1989). Therefore, although at least some simple visual functions can be reconstituted, the restoration of patterned vision would require the re-establishment of a substantial number of topographically appropriate connections with host neurons, and this has yet to be demonstrated in mammals.

\section{Conclusions}

This study shows that although the mature mammalian brain is less conducive than the immature brain to the proper development of retinal grafts and the outgrowth of their axons, a working circuit can nevertheless be established with the host brain. This circuit is capable of relaying luminance information encoded by the graft to neurons of the host brain which, in turn, respond to this input by performing the appropriate visceromotor function. Therefore, the graft-mediated pupillary reflex serves as a straightforward assay for the establishment of both functional graft-host connections and the necessary intraretinal functions. Combined with other work in this area, the present study supports the feasibility of using the mature rat as a model system in which to study the efficacy of neural grafting as a potential therapy for brain damage in which a relay system has been disrupted.

\section{References}

Aguayo, A. J., S. David, and G. M. Bray (1981) Influences of the glial environment on the elongation of axons after injury. J. Exp. Biol. 95: 231-240.

Azmitia, E. C., and A. Björklund, eds. (1987) Cell and Tissue Transplantation into the Adult Brain, Ann. N.Y. Acad. Sci. 495: 1-812.

Bartus, R. T. (1987) Neural tissue transplantation: Comments on its role in general neuroscience and its potential as a therapeutic approach. Ann. N.Y. Acad. Sci. 495: 355-361.

Björklund, A., and U. Stenevi (1979) Reconstruction of the nigrostriatal dopamine pathway by intracerebral nigral transplants. Brain Res. 177: 555-560.

Björklund, A., U. Stenevi, and N.-Aa. Svendgaard (1976) Growth of transplanted monoaminergic neurones into the adult hippocampus along the perforant path. Nature 262: 787-790.

Björklund, A., S. B. Dunnett, U. Stenevi, M. E. Lewis, and S. D. Iversen (1980) Reinnervation of the denervated striatum by substantia nigra transplants: Functional consequences as revealed by pharmacological and sensorimotor testing. Brain Res. 199: 307-333.

Björklund, A., O. Lindvall, O. Isacson, P. Brundin, K. Wictorin, R. E. Strecker, D. J. Clarke, and S. B. Dunnett (1987) Mechanisms of action of intracerebral neural implants: Studies on nigral and striatal grafts to the lesioned striatum. TINS 10: 509-516.

Björklund, A., P. Brundin, and O. Isacson (1988) Neuronal replacement by intracerebral neural implants in animal models of neurodegenerative disease. In Advances in Neurology, S. G. Waxman, ed., pp. 455-492, Raven, New York.

Blair, J. R., and J. E. Turner (1987) Optimal conditions for successful transplantation of immature rat retina to the lesioned adult retina. Dev. Brain Res. 36: 257-270.

Bok, D., and J. Heller (1976) Transport of retinol from the blood to the retina: An autoradiographic study of the pigment epithelial cell surface receptor for plasma retinol binding protein. Exp. Eye Res. 22: 395-402.

Bregman, B. S., and P. J. Reier (1986) Neural tissue transplants rescue axotomized rubrospinal cells from retrograde death. J. Comp. Neurol. 244: 86-95.

Broadwell, R., W. Hickey, and A. Wolf (1988) Angiogenesis in intracerebral grafts of CNS and pituitary tissues. Soc. Neurosci. Abstr. 14: 763.

Buzsaki, G., and F. H. Gage (1988) Neural grafts: Possible mechanisms of action. In Neural Plasticity: A Lifespan Approach, T. L. Petit and G. O. Ivy, eds., pp. 171-199, Liss, New York.

Campbell, G., and A. R. Lieberman (1985) The olivary pretectal nucleus: Experimental anatomical studies in the rat. Philos. Trans. R. Soc. Lond. (Biol.) 310: 573-609.

Clarke, R. J., and H. Ikeda (1985) Luminance and darkness detectors 
in the olivary and posterior pretectal nuclei and their rclationship to the pupillary light reflex in the rat. Exp. Brain Res. 57: 224-232.

Craner, S. L., J. D. Radel, L. S. Jen, and R. D. Lund (1989) Lightevoked cortical activity produced by illumination of intracranial retinal transplants: Experimental studies in rats. Exp. Neurol. 104: 93100.

Deckel, A. W., R. G. Robinson, J. T. Coyle, and P. R. Sandberg (1983) Reversal of long-term locomotor abnormalities in the kainic acid model of Huntington's disease by day 18 fetal striatal implants. Eur. J. Pharmacol. 93: 287-288.

Deckel, A. W., T. H. Moran, J. T. Coyle, P. R. Sanberg, and R. G. Robinson (1986) Anatomical predictors of behavioral recovery following fetal striatal transplants. Brain Res. 365: 249-258.

Del Cerro, M., D. M. Gash, G. N. Rao, M. F. Notter, S. J. Wiegand, and C. Del Cerro (1985) Intraocular retinal transplants. Invcst. Ophthalmol. Vis. Sci. 26: 1182-1185.

Del Cerro, M., D. M. Gash, G. N. Rao, M. F. Notter, S. J. Wiegand, S. Sathi, and C. Del Cerro (1987) Retinal transplants into the anterior chamber of the rat eye. Neuroscience 21: 707-724.

Dowling, J. E. (1960) Chemistry of visual adaptation in the rat. Nature 188: 114-118.

Freed, W. J., and R. J. Wyatt (1980) Transplantation of eyes to the adult rat brain: Histological findings and light-evoked potential response. Life Sci. 27: 503-510.

Gage, F. H., A. Björklund, U. Stenevi, S. B. Dunnett, and P. A. T. Kelly (1984) Intrahippocampal septal grafts ameliorate learning impairments in aged rats. Science 225: 533-536.

Gage, F. H., U. Stenevi, T. Carlstedt, G. Foster, A. Björklund, and A. J. Aguayo (1985) Anatomical and functional conscquences of grafting mesencephalic neurons into a peripheral nerve "bridge" connected to the denervated striatum. Exp. Brain Res. 60: 584-589.

Galli, L., K. Rao, and R. D. Lund (1989) Transplanted rat retinae do not project in a topographic fashion to the host tectum. Exp. Brain Res. 74: 427-430.

Gibson, M. J., D. T. Krieger, H. M. Charlton, E. A. Zimmerman, A.-J. Silverman, and M. J. Perlow (1984) Mating and pregnancy can occur in genetically hypogonadal mice with preoptic area brain grafts. Science 225: 949-951.

Isacson, I., P. Brundin, P. A. T. Kelly, F. H. Gage, and A. Björklund (1984) Functional neuronal replacement by grafted striatal neurons in the ibotenic acid-lesioned rat striatum. Nature 311: 458-460.

Isacson, O., S. B. Dunnett, and A. Björklund (1986) Graft-induced behavioral recovery in an animal modcl of Huntington discasc. Proc. Natl. Acad. Sci. USA 83: 2728-2732.

Klassen, H., and R. D. Lund (1987) Retinal transplants can drive a pupillary reflex in host rat brains. Proc. Natl. Acad. Sci. USA 84: 6958-6960.

Klassen, H., and R. D. Lund (1988a) Anatomical and behavioral correlates of a xenograft-mediated pupillary reflex. Exp. Neurol. 102: 102-108.

Klassen, H., and R. D. Lund (1988b) Retinal transplants can make functional connections with the mature mammalian brain. Soc. Neurosci. Abstr. 14: 1277.

Krieger, D. T., M. J. Perlow, M. J. Gibson, T. F. Davies, E. A. Zimmerman, M. Ferin, and H. M. Charlton (1982) Brain grafts reverse hypogonadism of gonadotropin releasing hormone deficiency. Nature 298: 468-472.

Lahav, M., D. M. Albert, and S. Wyand (1973) Clinical and histopathological classification of retinal dysplasia. Am. J. Ophthalmol. 75: 648-667.

La Vail, M. M., and W. Hild (1971) Histotypic organization of the rat retina in vitro. Z. Zellforsch. 114: 557-579.

Liesi, P. (1985) Do neurons in the vertebrate CNS migrate on laminin? EMBO J. 4: 1163-1170.

Lund, R. D., and J. S. Lund (1971) Modifications of synaptic patterns in the superior colliculus of the rat during development and following deafferentation. Vision Res. Suppl. 3: 281-298.

Lund, R. D., and S. C. McLoon (1983) Retinal transplants. In Neural Tissue Transplantation Research, R. B. Wallace and G. D. Das, eds., pp. 165-173, Springer-Verlag, New York.

Lund, R. D., and L. E. Westrum (1966) Neurofibrils and the Nauta method. Science 151: 1397-1399.

Lund, R. D., K. Rao, M. H. Hankin, H. W. Kunz, and T. J. Gill, III (1987) Transplantation of retina and visual cortex to rat brains of different agcs: Maturation, connection patterns and immunological consequences. Ann. N.Y. Acad. Sci. 495: 227-241.

Lund, R. D., K. Rao, H. W. Kunz, and T. J. Gill (1988) Instability of neural xenografts placed in neonatal rat brains. Transplantation 46: 216-223.

Lund, R. D., J. D. Radel, M. H. Hankin, H. Klassen, P. J. Coffey, and J. N. P. Rawlins (1989) Developmental and functional integration of retinal transplants with host rat brains. In Brain Repair, A. J. Aguayo and A. Björklund, eds., Macmillan, New York (in press).

Matthews, M. A., L. C. West, and R. V. Riccio (1982) An ultrastructural analysis of the development of foetal rat retina transplanted to the occipital cortex, a site lacking appropriate target neurons for optic fibers. J. Neurocytol. 11: 533-557.

McCaffery, C. A., M. R. Bennett, and B. Dreher (1982) The survival of neonatal retinal ganglion cclls in vitro is enhanced in the presence of appropriate parts of the brain. Exp. Brain Res. 48: 377-386.

McLoon, S. C., and R. D. Lund (1980) Specific projections of retina transplanted to rat brain. Exp. Brain Res. 40: 273-282.

McLoon, S. C., and R. D. Lund (1983) Development of fetal retina, tectum, and cortex transplanted to the superior colliculus of adult rats. J. Comp. Neurol. 217: 376-389.

McLoon, S. C., L. K. McLoon, S. L. Palm, and L. T. Furcht (1988) Transient expression of laminin in the optic nerve of the developing rat. J. Neurosci. 8: 1981-1990.

Needels, D. L., M. Nieto-Sampedro, and C. W. Cotman (1986) Induction of a neurite-promoting factor in rat brain following injury or deafferentation. Neuroscience 18: 517-526.

Nieto-Sampedro, M., M. Manthorpe, G. Bardin, S. Varon, and C. W. Cotman (1983) Injury-induced neuronotrophic activity in adult rat brain: Correlation with survival of delayed implants in the wound cavity. J. Neurosci. 3: 2219-2229.

Perry, V. H., and R. D. Lund (1989) Microglia in retinae transplanted to the central nervous system. Neuroscience $31: 453-462$.

Rosenberg, M. B., T. Friedmann, R. C. Robertson, M. Tuszynski, J. A. Wolff, X. O. Breakfield, and F. H. Gage (1988) Grafting genetically modified cells to the damaged brain: Restorative effects of NGF expression. Science 242: 1575-1578.

Rosenstein, J. M. (1987) Neocortical transplants in the mammalian brain lack a blood-brain barrier to macromolecules. Science $881: 772$ 774.

Sefton, A. J., R. D. Lund, and V. H. Perry (1987) Target regions enhance the outgrowth and survival of ganglion cells in embryonic retina transplanted to cerebral cortcx in nconatal rats. Dev. Brain Res. 33: $145-149$.

Siegel, S. (1956) Nonparametric Statistics for the Behavioral Sciences, McGraw-Hill, New York.

Simons, D. J., and R. D. Lund (1985) Fetal retinae transplanted over tecta of neonatal rats respond to light and evoke patterned neuronal discharges in the host superior colliculus. Dev. Brain Res. 21: 156159.

So, K.-F., and A. J. Aguayo (1985) Lengthy regrowth of cut axons from ganglion cells after peripheral nerve transplantation into the retina of adult rats. Brain Res. 328: 349-354.

Svendgaard, N.-Aa., A. Björklund, J.-E. Hardebo, and U. Stenevi (1975) Axonal degeneration associated with a defective blood-brain barrier in cerebral implants. Nature 255: 334-339.

Tansley, K. (1933) The formation of rosettes in the rat retina. Br. J. Ophthalmol. 17: 321-336.

Trejo, L., and C. M. Cicerone (1984) Cells in the pretectal olivary nucleus are in the pathway for the direct light reflex of the pupil in the rat. Brain Res. 300: 49-62.

Tso, M. O. M., B. S. Fine, and L. E. Zimmerman (1969) The FlexnerWintersteiner rosettes in retinoblastoma. Arch. Pathol. 88: 665-671.

Turner, J. E., and J. R. Blair (1986) Newborn rat retinal cells transplanted into a retinal site in adult host eyes. Dev. Brain Res. 26:91104.

Vidal-Sanz, M., G. M. Bray, M. P. Villegas-Perez, S. Thanos, and A. J. Aguayo (1987) Axonal regeneration and synapse formation in the superior colliculus by retinal ganglion cells in the adult rat. J. Neurosci. 7: 2894-2909.

Young, R. W., and D. Bok (1969) Participation of the retinal pigment epithelium in the rod outer segment renewal process. J. Cell Biol. 42. $392-402$. 